\title{
Women's Experiences with Gender Violence and the Mental Health Impact: Qualitative Findings
}

\author{
Venus Medina Maldonado ${ }^{1}$, Margarete Landenberger ${ }^{1}$, Marbella Camacaro Cuevas ${ }^{2}$ \\ ${ }^{1}$ Institute for Health and Nursing Science, Faculty of Medicine, Martin Luther University (Halle-Wittenberg), \\ Halle (Saale), Germany \\ ${ }^{2}$ Research Unit for Gender Studies "Bellacarla Jirón Camacaro", Faculty of Health Sciences, University of \\ Carabobo, Valencia, Venezuela \\ Email: ${ }^{\text {medinav@uc.edu.ve }}$
}

Received 20 January 2015; accepted 2 February 2015; published 6 February 2015

Copyright (C) 2015 by authors and Scientific Research Publishing Inc.

This work is licensed under the Creative Commons Attribution International License (CC BY). http://creativecommons.org/licenses/by/4.0/

(c) (i) Open Access

\section{Abstract}

The purpose of this study was to describe women's experiences with gender violence and the impact on mental health. The research was a qualitative observational study. Participants were $n=$ 72 women clients of (02) Primary Health Centers at the University of Carabobo-Venezuela. The technique to gather the information was focus group discussion (FGD). The interpretation of data was an analytical process based on Mayring's approach. The principal findings showed that, women clients of primary health centers experienced different levels of violence in everyday life. Physical violence was the most frequent abuse reported by victims. Death threats were the most frequent conduct used by the partners in terms of psychological violence. Women expressed being under the control of a dominant partner without physical aggression or threats, but they felt a lack of autonomy. Additionally, women who experienced different levels of abuse specified some symptoms that could suggest an impact on mental health. In conclusion, women naturalized dominance and control because they understood this kind of abuse as normal behavior between relationship partners.

\section{Keywords}

Violence against Women, Mental Health, Primary Health Care

\footnotetext{
${ }^{*}$ Corresponding author.
} 


\section{Introduction}

In Venezuela, the health team that works in a primary health center offers basic assistance to individuals and families in the community. They support at the local and referral levels. Particularly, community health nurses direct its actions towards health promotion, illness prevention and studies of risk factors in the different population groups.

The work achieved by community health nurses facilitates the connection between the population and health services offered by primary health centers because they do activities outside of health centers, such as domiciliary visits, educative activities in schools, high schools, or communitarian organizations.

This close contact with the community enabled them to know the reality as seen by people, because the discursive interaction between the participants and nursing staff facilitates the communication of people's needs and expectations. During these encounters and consultations, violence in the population, including gender violence, was observed frequently.

Specifically, in two (02) primary health centers at the University of Carabobo-Venezuela the empirical evidence showed not only women's experiences with gender violence also consequences in mental health. It was the main motivation to develop this study. In addition, international studies among women showed that Intimate Partner Violence is related to greater post-traumatic stress disorder symptom severity [1] [2].

Regarding epidemiological information, mortality data from homicide during 2009 among Venezuelan women between 15 - 64 years old was $n=528$ females [3]. However, in Venezuela it's very difficult to know the exact prevalence of gender violence from official institutions because there are no updated statistics. In addition, there are difficulties to approach this problem with gender perspective in patriarchal institutions [4].

Furthermore, this qualitative study with gender perspective aimed to describe women's experiences with gender violence as well as its impact on mental health in two (02) primary health centers.

\section{Methods}

A qualitative study with gender perspective was carried out in (02) Primary Health Centers at the University of Carabobo in Valencia, Venezuela. Participants were selected from a convenience sample and, before starting the discussion, were informed about the aims of the study as well as the confidential and voluntary nature of the research, and were given information consent forms to sign, too [5]. Participants were $n=72$ women and the considered selection criteria were being female, over age 17, and being client of these university health centers. The time exposition with violence was not specified by participants during the grupal discussion.

The technique selected in data collection was Focus Group Discussion (FGD) because it keeps to a minimum the distance between researchers and participants, this characteristic is compatible with the feminist epistemological framework [6]. Data were collected from Feb. 2010 to Jul. 2010. Discussions were recorded and stored in voice files using a digital recorder. The systematization of the data was handled with the software Atlas ti 6.2. The Mayring's approach was used for the interpretative process.

\section{Results}

These results offer insight into participants' experiences with gender violence and impact in mental health. At the beginning of study, women were asked about their understanding with respect to abusive relationships. However, the communicative dynamic during the exchange displayed some women starting to speak spontaneously about their experiences with gender violence. They explained their feelings, and also the reasons as to why they did not seek help.

Analysis revealed the following themes: "Dominance and control over one’s partner”, "Victims of physical and psychological violence" and "Mental health impact”. A total of ( $n=31 / 72)$ women clients of the primary health centers said their experiences involved abusive behaviors by partners, ex-partners, sons or grandsons.

Code: Dominance and control over one’s partner (06/72).

GF1/P3: "I want study but my husband does not allow it".

GF4/P3: "My husband tells me: you are responsible for everything at home but it was assigned in a bad way”.

GF6/P7: "I must leave my work because my husband does not want me to work".

GF7/P2: "I did not finish either my studies or work because my husband did not allow me to". 
GF7/P9: “Usually I don’t leave home, only when necessary because I don’t like to have problems with my partner”.

On the other hand, women clients of primary health centers mentioned being or having been victims of physical violence $(n=20 / 72)$ and psychological violence $(n=05 / 72)$ by partners, ex-partners or relatives. In this group a total $(n=4 / 09$ aged $>65$ years) older women were victims of physical and psychological violence by sons or grandsons.

Code: Physical violence (20/72).

FG1/P6: "My grandsons 31 and 32 years old hit me, and they hit my daughter too".

FG3/P4: "He hit me like I was a man".

FG3/P2: "In 32 years of marriage. Of course! We have experienced physical violence”.

Code: Psychological violence (05/72).

FG5/P2: "Always he yells, threatens, scares and follows me".

FG7/P3: "He says me: I will kill you".

FG7/P6: "My son and my ex-partner live at home, but they only know: "yell, threaten, humiliate me and to say the worst things to me" Observation: She remained in silence a few seconds and then began to cry.

The theme "Mental health impact" collected expressions of the women affected by gender violence and it involved three codes: fear $(n=25 / 31)$; low self-esteem $(n=5 / 31)$; and mental suffering $(n=19 / 31)$.

Code: Fear (25/31).

FG2/P11: "One is always scared to report because institutions are indifferent to face this problem”.

FG3/P6: "One fears violent men because they threaten with killing the family".

FG7/P7: "I am saying it, but I am saying with a lot of fear".

Code: Low self-esteem (5/31).

FG5/P5: "I feel small".

FG5/P3: "I thought if he has an affair, it's just because I'm good for nothing”.

FG6/P7: "I feel too much like an incompetent woman to face the life alone".

Code: Mental suffering (19/31).

FG1/P5: "I feel unhappy" Observation: Participant began to mourn.

FG4/P4: "I felt pain in my soul, torment. Right now I'm separated but I am not at peace”.

FG6/P6: "The life is horrible” Observation: Participant began to mourn.

\section{Discussion}

The results in this study indicate different scales of abuse. First, "Dominance and control over one's partner”. This theme codified expressions in which women described typical signs of an abusive relationship. Women narrated their experiences with: control over what they're doing, where they're going, who they're visiting, how they dressed, and the impediment of other personal decisions like studying or working.

Additionally, the expressions of women were filled with fear and frustration. It showed clearly unhealthy relationships and abuse. However, they did not feel they were victims [7]. Women recognized this conduct could cause a progressive dependence, but it was minimized by them because it was understood as a normal behavior in gender relationships.

Second, "Victims of physical and psychological violence" $n=20 / 72$ women described their life experiences with physical abuse such as beating, hitting, dragging, or pushing. In this group of victims also older women (n $=03 / 09$ aged $>65$ years) told stories of abuse in which sons and grandsons were the aggressors.

About psychological violence, $n=5 / 72$ victims described being: threatened, degraded and humiliated. In this group of participants older women ( $n=1 / 09$ aged $>65$ years) were also identified. Older women admitted to being or having been victims of gender violence by their partner, ex-partner or sons.

Other information, they did not make contact with the police to report the abuse. Basic explanations why they did not report: lack of confidence in institutions, fear and the fact that women considered the use of violence to be a norm in conflict resolution between genders [8] [9].

In the medical history form of each client it was observed that there was no information about their violence 
situation. It could suggest under-registration because official institutions had no evidence indicating that these women were victims of gender violence. In this study, women that reported being victims and did not seek help remain with risk exposure to violence.

Third, "Mental health impact" in general women who experienced different levels of abuse (including older women) expressed feeling unhappiness, hopelessness and a lack of meaning in existence. It could suggest symptoms of depression or psychological distress [10] [11]. It was registered as "Low self-esteem" and "Mental suffering".

Observable in victims of mild forms of violence was "Dominance and control over one's partner" as well as, in older women with more evident forms, "Victims of physical and psychological violence". "Fear" was a common code in both cases. It was obvious through the exercise of coercive power; the perpetrator creates the expectancy of negative consequences [12].

Most of the women participants in this study confirmed it was the first time that they had spoken with the health team about their problem. A limit was observed in this study related to the technique used (FGD) regarding consequences in the mental health of women, because gender violence operates with different levels of abuse and psychological aspects must be deeply examined.

\section{Conclusions}

Dominance and control were naturalized by women because they understood this kind of abuse as normal behavior between relationship partners. Older women are or had been victims of gender violence from their partner, expartner, sons or grandsons. In this group, it was evident that patriarchal norms have influenced gender relation into families.

Other significance in this study, health teams belonging to these kinds of health centers must be developed (screening, register and assistance of gender violence cases) in order to visualize the magnitude of the gender violence problem in our society and its effects on population health.

\section{References}

[1] Campbell, J. (2002) Health Consequences of Intimate Partner Violence. The Lancet, 359, 1331-1336. http://dx.doi.org/10.1016/S0140-6736(02)08336-8

[2] Sullivan, T., Cavanaugh, C., Buckner, J., and Edmondson, D. (2009) Post Traumatic Testing Posttraumatic Stress as a Mediator of Physical, Sexual, and Psychological Intimate Partner Violence and Substance Problem among Women. Journal of Traumatic Stress, 22, 575-584. http://ncbi.nlm.nih.gov/pmc/articles/PMC3012603/

[3] Ministry of Health (2009) MPPS Datos de Mortalidad-Anuario estadístico. Ministerio del Poder Popular para la Salud, Republica Bolivariana de Venezuela.

[4] Ministry for the Woman and Gender Equality (2010) Report of Public Policies Directed towards Women: Results 1999-2009. Bolivarian Observatory of Gender. Ministerio del Poder Popular para la Mujer y la Igualdad de Género, Republica Bolivariana de Venezuela.

[5] Ministry of Science and Technology (2002) Bioethics and Biosafety Code. Ministerio del Poder Popular para Ciencia, Tecnología e Innovación, Republica Bolivariana de Venezuela.

[6] Medina-Maldonado, V. (2014) Public Health Program Based on the Evidence of Nursing for Prevention and Assistance of Gender-Based Violence in Collaboration with Specialized Personnel and Community Members. Ph.D. Thesis, Universitaet Martin Luther (Halle-Wittenberg) Medizinische Fakultaet, 80 p.

[7] Medina-Maldonado, V., Camacaro Cuevas, M. and Torres, L. (2011) Construcciones subjetivas sobre la Violencia de Género. Aportes para la prevención del problema. Enfermeria Global, 10, 346-358.

http://dialnet.unirioja.es/servlet/articulo?codigo=3685036 http://dx.doi.org/10.4321/S1695-61412011000300023

[8] Fugate, M., Landis, L., Riordan, K., Naureckas, S. and Engel, B. (2005) Barriers to Domestic Violence Help Seeking: Implications for Intervention. Violence against Women, 11, 290-310. http://vaw.sagepub.com/content/11/3/290.short http://dx.doi.org/10.1177/1077801204271959

[9] Meneghel, S.N., Bairros, F., Mueller, B., Monteiro, D., Oliveira, L.P. and Collaziol, M.E. (2011) Critical Trajectories of Female Victims of Gender Violence: Discourse Analysis of Women and Staff Professionals in Porto Alegre, Rio Grande do Sul State, Brazil. Cadernos Saúde Pública, 27,743-752. http://www.scielo.br/pdf/csp/v27n4/13.pdf http://dx.doi.org/10.1590/S0102-311X2011000400013

[10] Moura, L.B., Lefevre, F. and Moura, V. (2012) Narratives of Intimate Partner Violence Practiced against Women. 
Ciência Saúde Coletiva, 17, 1025-1035. http://bvsalud.org/portal/resource/en/mdl-22534856

[11] Vives-Cases, C., Ruiz-Cantero, M.T., Escribà-Agüir, V. and Miralles, J.J. (2011) The Effect of Intimate Partner Violence and Other Forms of Violence against Women on Health. Journal of Public Health (Oxford), 33, 15-21. http://jpubhealth.oxfordjournals.org/content/33/1/15 http://dx.doi.org/10.1093/pubmed/fdq101

[12] Keeling, J. and Fisher, C. (2012) Women’s Early Relational Experiences That Lead to Domestic Violence. Qualitative Health Research, 22, 1559-1567. http://www.ncbi.nlm.nih.gov/pubmed/22910590 
Scientific Research Publishing (SCIRP) is one of the largest Open Access journal publishers. It is currently publishing more than 200 open access, online, peer-reviewed journals covering a wide range of academic disciplines. SCIRP serves the worldwide academic communities and contributes to the progress and application of science with its publication.

Other selected journals from SCIRP are listed as below. Submit your manuscript to us via either submit@scirp.org or Online Submission Portal.
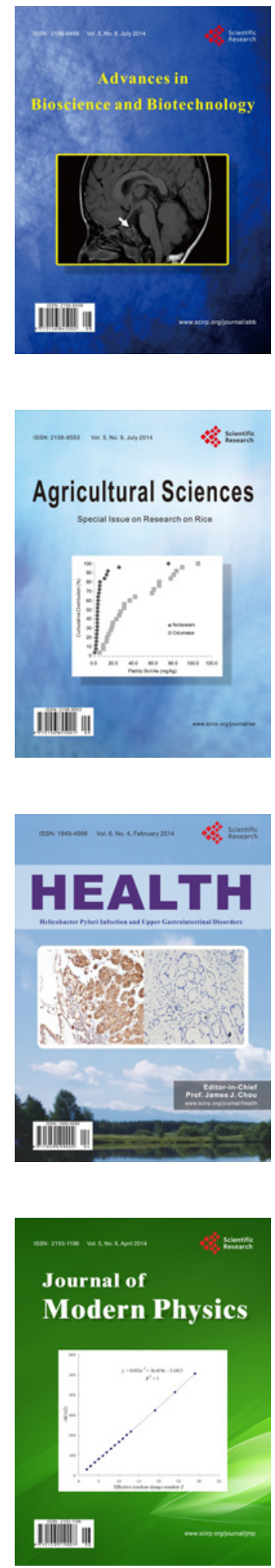
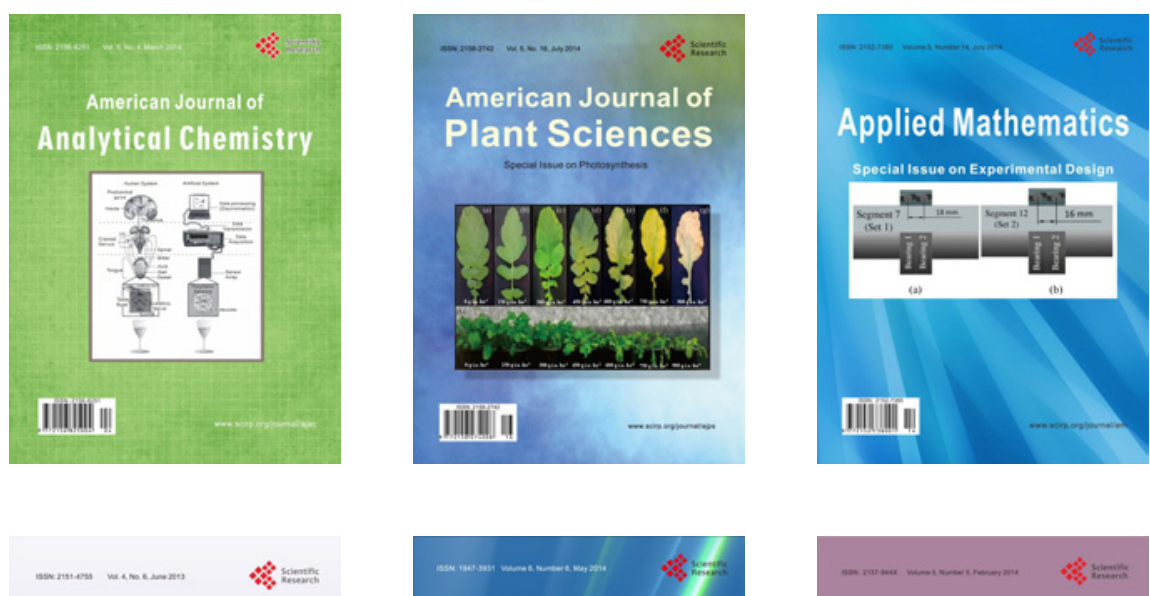

Creative Education
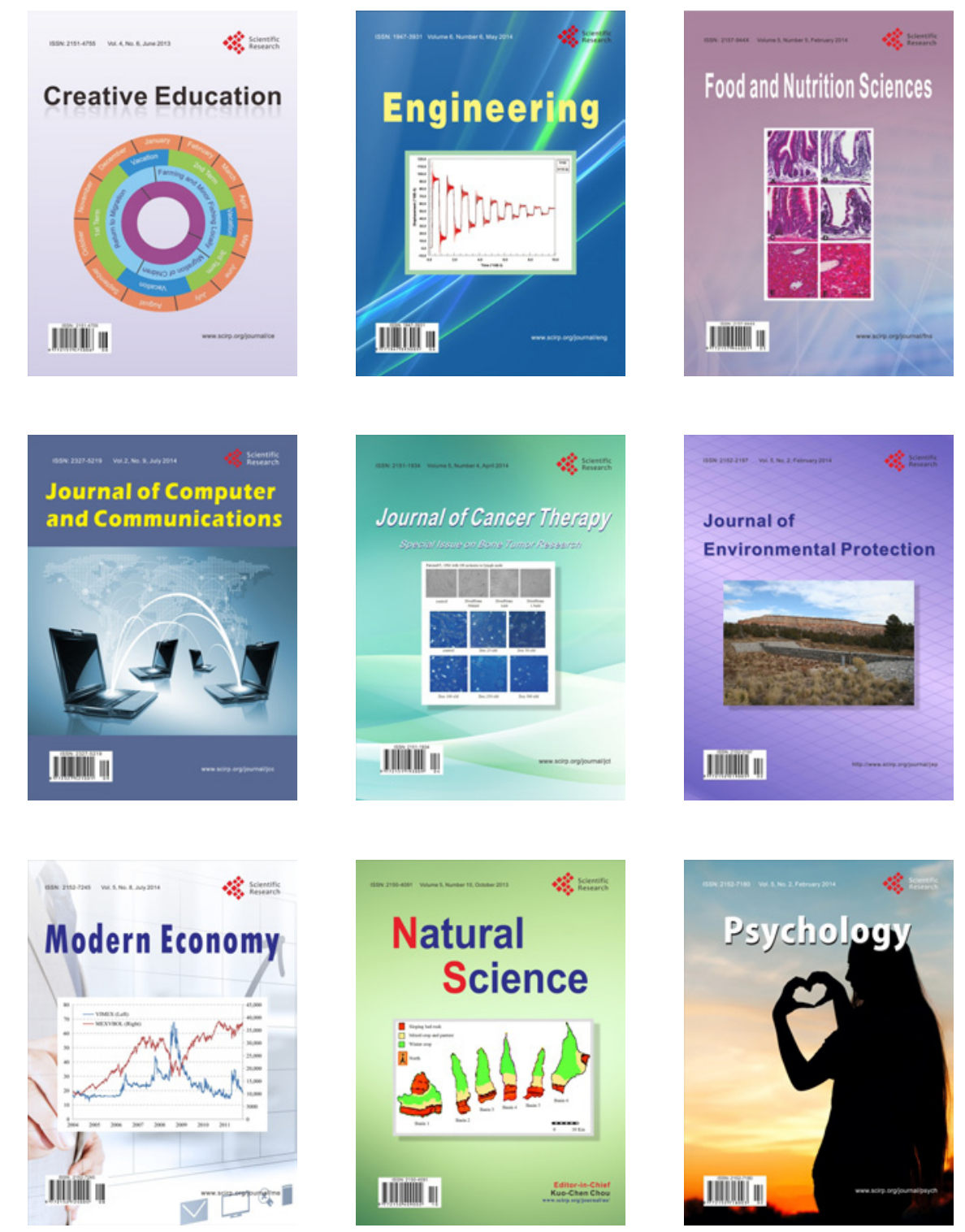